\title{
A EXPERIÊNCIA DO COTIDIANO EM J. M. COETZEE: LÍNGUA E IDENTIDADE EM BOYHOOD, SCENES OF PROVINCIAL LIFE, A MEMOIR (1998)
}

\section{Vera Lucia Harabagi Hanna*}

Resumo: O objetivo deste artigo é o de pesquisar controversas atitudes do escritor J. M. Coetzee em relação à língua inglesa e ao africâner em seus escritos e, por extensão, sua visão sobre o sentido de ambas as línguas em Boyhood, scenes of provincial life, a memoir (1998). Refletimos sobre passagens da (auto) biografia ficcionalizada explorando a problemática da identidade e a escolha-uso de língua na África do Sul. Procuramos, parcialmente, entender a relação de seu texto com os paradoxos da representação binária de ficção/história, do particular/geral, do presente/passado.

Palavras-chave: Lingua. Identidade. J. M. Coetzee.

Great poets can tell their own stories without once saying "I", and in doing so, lend their voice to all humanity (PAMUK, 2013, p. BR7).

\section{INTRODUÇÃO: ESTRATÉGIAS DE SUBJETIVAÇÃo - SINGULAR E/OU COLETIVA}

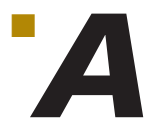

s literaturas pós-colonialistas têm dado ensejo a questionamentos sobre história e ficção (história e legitimidade), narratividade e ambiguidade, tempo e espaço, além de indagações fundamentais sobre lugar, língua e identidade. Observados no cotidiano de um indivíduo através das práticas do dia a dia, a contextualização do ordinário sugere o entendimento de que atos rotineiros não contêm uma história singular, mas existem em miriades de histórias. Em análises dedicadas a lugares-comuns da existência, em repetidas ações, a narrativa pode ser transformada em uma visão global sob senso comum. A noção de cotidianidade ligada à ideia de singularidade que procuramos nos textos de John Maxwell Coetzee encontra-se representada em persistentes problemas culturais-linguísticos que existem nas entrelinhas das práticas diárias. Conforme Highmore (2002a, 2002b) e De Certeau (1980), teó- 
ricos do cotidiano explicitam a relação que conecta a busca diária a circunstâncias particulares que implica ideias coletivas.

A noção de cotidiano, que sugere ambivalência, de Highmore (2002a), coaduna-se com a leitura de autrebiography, de J. M. Coetzee, em vários aspectos, consoante a análise que aqui empreendemos. $\mathrm{O}$ foco da ideia nas ações mais repetidas, e mais próximas do indivíduo, poderão acarretar, simultaneamente, sensações de tédio, de opressão, percebidas de modo confuso ou de modo claro, que provocam algumas vezes prazer, outras, conflito. O atributo das ações mais repetidas quem sabe constitua, paradoxalmente, a própria ausência de atributos, "talvez seja, precisamente, aquilo que não é notado, o imperceptível, o invisível, o discreto", esclarece Highmore (2002a, p. 2), que defende ser a ambivalência o próprio registro da modernidade, determinante de intricada ligação binária, "o que acontece quando aquele mundo é desestabilizado e interrompido pelo não-familiar?”. Acrescentamos que a tensão entre o familiar e o novo também pode provocar um processo dinâmico de esforço para incorporar o inusitado, para tornar o não familiar, familiar, o não habituado, habituado, para ajustar diferentes modos de viver - pela razão de sucessos e colapsos marcarem o dia a dia pode "o novo tornar-se tradicional, assim como os resíduos do passado tornarem-se anacrônicos e disponiveis para renovação" (HIGHMORE, 2002a, p. 2). Highmore insiste ainda que hiatos ocorrem com frequência em toda parte, portanto, a linguagem do cotidiano não será garantia de aceitação do novo, podendo refletir frustrações com promessas rompidas.

Isto posto, e mantendo o compromisso de desenvolver o tema apresentado, focalizaremos o papel da localização/deslocalização/relocalização e da língua na constituição da identidade ambivalente - questões como localidade, e língua e identidade podem ser percebidas no dia a dia de uma só pessoa por meio das práticas do cotidiano em narrativas - essa textualização, lembramos mais uma vez, subentende a noção de ações diárias existentes em multíplices vidas. As abordagens dos estudos do cotidiano preocupam-se com o mundo da experiência comum, encarando-a como problemática, como aponta o historiador Peter Burke (1992, p. 23), especialmente "no sentido de mostrar que o comportamento ou os valores, que são tacitamente aceitos em uma sociedade, são rejeitados como intrinsecamente absurdos em outra".

A ideia de que a história social e a cultura dissolvem-se uma na outra e a inevitabilidade do impacto do relativismo cultural sobre o escrito histórico, de Burke, reflete-se, do mesmo modo, no entendimento de Homi Bhabha (2005, p. 20), no sentido de como as narrativas de subjetividade devem focalizar processos produzidos na articulação das diferenças culturais, e passar além das originárias e iniciais, os "momentos ou processos que são produzidos na articulação de diferenças culturais". Desde que, segundo ele, os sujeitos se formam nos excedentes da soma das partes da diferença, "esses 'entre-lugares' fornecem o terreno para a elaboração de estratégias de subjetivação - singular ou coletiva”, que darão ensejo "a novos signos de identidade e postos inovadores de colaboração e contestação, no ato de definir a própria ideia de sociedade” (BHABHA, 2005, p. 20). Retornemos nesse ponto a Burke (2005, p. 24-25), que abaliza o cotidiano como não eterno, relacionando a mudança aos grandes acontecimentos que penetram no dia a dia dos diferentes grupos sociais; assim, a Reforma, a Revolução Francesa, a Revolução Russa, citadas como exemplos, poderiam indicar a correlação entre acontecimentos politico-econômico-sociais marcantes e as estruturas da vida cotidiana. 
Vale admitirmos que a contextualização do cotidiano, a ser observada em Boyhood, scenes of provincial life, a memoir (1998), implica cuidar da história particular do autor-narrador-protagonista que, idênticos quando se trata de autobiografia, diferem na narrativa de Coetzee - embora o autor e o protagonista possam ser vistos como únicos, o protagonista, em sua narrativa, é referido em terceira pessoa e de modo omnisciente. O termo "autrebiography", adotado por Coetzee, carrega um jogo de palavras em que o termo "autre", em francês, remete a "outro" e não a "auto"; frequentemente associado ao seu estilo, o autor passa por cima da noção de autobiógrafo, afasta-se de sua subjetividade, livra-se da obrigatoriedade de contar a verdade. A questão da narrativa, e do que se pode chamar de "autobiografia pouco convencional" (autobiografia ficcionalizada), encarada do ponto de vista narratológico, assim como o problema da verdade, são pontos muito discutidos por críticos literários que se assentam em ensaios, entrevistas, resenhas críticas do próprio Coetzee, nos quais deixa claro que está mais interessado no valor da própria narrativa do que no mecanismo pelo qual a verdade é reportada.

Questões como as elencadas podem revelar nelas mesmas a identidade do autor, já que suas narrativas contextualizam problemas familiares, com a cultura étnica, com a lingua assumida. Em Doubling the point: essays and interviews, declaradamente um texto autobiográfico, Coetzee (1992) polemiza a ideia de autrebiography em vários pontos das entrevistas ali reproduzidas - selecionamos passagens do primeiro e dos últimos capítulos (p. 17-30; p. 391-394, respectivamente) que elucidam a tomada de posição sobre a adoção do termo. Relaciona-a diretamente à questão da verdade, "Como saberei quando eu realmente tenho a verdade a respeito de mim mesmo?” (p. 17), porquanto, segundo ele, deveríamos distinguir entre dois tipos de verdade, a verdade do fato e algo que vai além dele, o que chama de mais alta verdade. Ao conferir como verdade que toda escrita é autobiográfica, "toda autobiografia é contação de histórias, e toda escrita é autobiografia" ("all autobiography is storytelling, all writing is autobiography") (p. 391), ele levanta mais uma vez a questão do fato: "Como contar a verdade na autobiografia?" (p. 392). Professa que o artefato é dominado por interesse próprio, e o escritor é o único com acesso privilegiado às informações; não demora a declarar que, nesse caso, traçar uma linha entre o passado e o presente é uma questão de autointeresse. Sob sua ótica, a autobiografia é apresentada como uma atividade biográfica, um tipo de narrativa cujo material é selecionado de um passado vivido e moldado em uma história que leva ao presente, mas ao mesmo tempo deve demonstrar continuidade entre o passado e o presente.

$\mathrm{Na}$ leitura aqui desenvolvida, tratamos a ideia de autobiografia ficcionalizada associada a um agente de temporalidades que desafia relatar o que foi vivido ou observado no enredo de eventos cotidianos, seguindo o que o próprio Coetzee nos indica - "em termos amplos, toda escrita é autobiográfica: tudo o que você escreve, incluindo crítica e ficção, é uma escrita sobre você mesmo enquanto você a escreve" (COETZEE, 1992, p. 17) - e que se excede pela qualidade de decodificar experiências, aspirações e crenças que, registradas em fatos e ficção de lugares-comuns, revelam ocorrências mais ou menos relevantes. A ideia de re- 
gistro autobiográfico, de testemunho, de escrito confessional, de auto-história ${ }^{1}$, envolve a ideia de interpretação - atentando que as interpretações podem se expandir, o critério de verdade é transformado na verdade do texto e, sendo revelado em um contexto, incontáveis interpretações poderão, portanto, surgir. Coetzee enfatiza a impraticabilidade de se contar a verdade plena justificando que a verdade porta fatos em demasia - "Você conta a história de sua vida selecionando fatos de um reservatório de memórias e, no processo de seleção, você deixa muitas coisas para trás" (COETZEE, 1992, p. 17). Ao tentar definir autobiografia, atesta que se trata de uma espécie de autoescrita "em que você é constrangido a respeitar os fatos de sua própria história. Mas quais fatos? Todos os fatos?" (COETZEE, 1992, p. 18), pergunta ele, para prontamente responder, que "todos" os fatos significaria fatos demais - "Você escolhe os fatos na medida em que eles possam preencher seus propósitos" (COETZEE, 1992, p. 18) - a verdade aparece no processo da escrita, ou, segundo ele, aparece com o processo de escrita.

\section{Língua E IDENTIDAde EM BOYHOOD, SCENES OF PROVINCIAL LIFE, A MEMOIR (1998)}

Antes de passarmos à leitura centrada em momentos pessoais de falta (ou não) de intimidade com a lingua africâner e/ou com a língua inglesa, além do sentimento de pertencimento de Coetzee como sul-africano, devemos acrescentar que essas indagações são possivveis pelo fato de examinarmos os escritos de Coetzee de um modo contextualizado, ou seja, a partir da noção de que são escritos sobre a África do Sul e a partir da África do Sul (ATTWELL, 1993). A infância do escritor, nascido em 1940, na Cidade do Cabo, conturbada por conflitos culturais em consequência de ser branco e falante de inglês, mas em certas ocasiões optar pelo africâner, explica a admissão de duas línguas (dentre as 11 línguas oficiais no país), decorrência da colonização desregrada da África do Sul, no século XVII, disputada por ingleses e holandeses pelo assenhoramento das minas de ouro e diamantes. O fato de o pai de Coetzee ser de origem africâner e não assumir essa identidade completamente, e a mãe, de origem alemã, meio-africâner, além de ambos conflituosamente assumirem o inglês como língua materna da família, pode aclarar parte das adversidades identitárias insolúveis oriundas dessa origem mista que perpassam sua obra. Em Boyhood, o status bilingue assumido pelo protagonista mostra, igualmente, o relacionamento de Coetzee com ambos os idiomas, e, apesar de pertencer a uma família que resiste à língua e à cultura africâner, é visto como um aspecto marcante de sua identidade e posição política, resultante da escolha de uma educação realizada basicamente em termos ingleses - um espécie de autoexilio, define Head (2009, p. 4) que o resguardaria da vida sul-africana, já que o termo "africâner" tornara-se símbolo de escolha política na segunda metade do século XX. Observemos seu posicionamento no capítulo 15 , dedicado aos pais:

O termo "authohistória" (assim como a teoria de "autohistoria"), cunhado pela escritora Gloria Anzaldua, vem ao encontro da abordagem de experiência do cotidiano-autrebiography, assumida em nosso artigo, pois, focalizado na história da vida pessoal, ou seja, como a "autohistoriadora" a conta, assim, Anzaldua admite, simultaneamante, contar a história de outros. "Escritores de autohistória", explica Ana Louise Keating (2009, p. 9, tradução nossa), "mesclam a teoria da autohistória, com suas biografias pessoais, com memoirs, com história, com mitos narrativos, e/ou com outras teorias que descrevem formas de relação de escritas autobiográficas que incluam não só história de vida, mas também o processo de escrita". 
Ele [o protagonista] agradece a Deus que sua mãe fale inglês. Mas permanece desconfiado a respeito do pai, apesar de Shakespeare e Wordsworth Ique ele lia] e das palavras cruzadas. Ele não consegue ver porque seu pai continua fazendo esforço para ser inglês aqui em Worcester, onde seria muito fácil para ele retomar seu lado africâner (COETZEE, 1998, p. 126).

O fato de os pais serem bilingues - anglófilo-africanos falantes -, o que talvez pudesse facilitar para o escritor reconhecer-se como inglês, promovera efeito contrário - as inglesidades chamavam a atenção do garoto em termos da incompatibilidade de perfil que o afastavam da possibilidade de compartilhamento de identidade - segundo Attwell (2015, p. 36), faziam o protagonista de Boyhood discordar que as identidades pudessem ser livremente escolhidas.

Ao discorrer sobre o nacionalismo e a escolha-uso da lingua do dia a dia, o africâner, Coetzee, ele mesmo, elucida tratar-se de um nome, e nomes são exercícios de poder, consequentemente, mais do que um rótulo línguístico ou cultural, é principalmente um termo carregado de ideologia. "Nenhum africâner me consideraria um africâner" (COETZEE, 1992, p. 341), razão da dificuldade em ser aceito por determinado grupo de reconhecidos escritores e críticos de seu país. A primeira definição de africâner, explica ele, é primeiramente, uma pessoa cuja primeira língua é o africâner, enquanto o inglês foi, desde seu nascimento, a língua doméstica; além disso, jamais pertencera à Igreja Reformada ou estivera envolvido diretamente com aquela cultura; desse modo, o questionamento recorrente é sobre como classificar-se como indivíduo no meio desse senso étnico-linguístico,

Eu sou uma das muitas pessoas neste país que se tornou apartado de suas raizes étnicas num lugar em que aquelas raizes foram sul-africanas-holandesas ou indonésias, ou britânicas ou gregas ou de quaisquer outros lugares e que têm se juntado a um grupo de etnos não reconhecidos cuja língua de comunicação (de troca) é o inglês. Essas pessoas não são, estritamente falando, "sul-africanos-ingleses”, já que um grande número delas - eu, inclusive - não são descendentes de britânicos. Eles são, meramente, sul-africanos (um mero nome de conveniência), cuja língua materna, a língua com a qual nasceram, é o inglês. Como o grupo não tem um etno perceptível, espero que um dia não haja mais cor predominante, já que mais "pessoas de cor" se misturarão e então, todas as diferenças se dissiparão” (COETZEE, 1992, p. 342).

Lembra principalmente que a relutância na adoção do termo africâner se dá por ter sido "sequestrado por um movimento político, primeiramente anti-britânico, mais tarde, nomeadamente, anti-negro, autointitulando-se 'Nacionalismo Africaner" (COETZEE, 1992, p. 342). Razões como essas, continua ele, tornaram o termo classificatório, impediram pessoas que, apesar de falarem africâner como primeira língua, mas por não apresentarem critérios raciais, culturais e políticos, não serem aceitos como africâners. Como resultado, sul-africanos negros, linguisticamente qualificados para usar o rótulo "africâner", hoje se recusam a usá-lo; do mesmo modo, inúmeros sul-africanos brancos repudiam, igualmente, legitimá-lo.

Aflições sobre a incerteza na escolha da língua em situações específicas perseguem-no constantemente quando criança, embora pudesse se sentir confortável em falar e entender as duas línguas, como vemos em excertos de Boyhood. O 
protagonista confessa o sentimento de se sentir um estranho, a ponto de desenvolver um senso de marginalidade social enquanto morou na zona rural de Worcester, entre 1948-1951. A problemática herança linguística, religiosa e política e os conflitos familiares, vividos em uma realidade hostil e violenta da África do Sul do pós-Segunda Guerra, aliada à identidade não definida dos pais, assombram o narrador-protagonista e reproduzem-se em Boyhood, em situações de intimidade familiar, como o encontro de Natal, narrado no capítulo 11 . A celebração se passa na fazenda pertencente aos familiares paternos - assumidos africâners - em que as mulheres se ocupam dos preparativos das refeições, enquanto os homens bebem e contam histórias dos velhos tempos. O trecho, citado a seguir, expõe uma inevitável comparação entre as três línguas faladas na ocasião e dá ideia de uma pequena parte da história colonialista do país. O ambiente de descontração revela-se na mistura do uso do inglês, do africâner aprendido na escola e do coloquial - aquela "lingua dançante" reproduz o caminho da Great Trek (em africâner Die Groot Trek), empreendido por migrantes de origem europeia, comumente dos Países Baixos, da Alemanha, além de franceses huguenotes que, descontentes com o controle britânico na região do Cabo, em meados de 1830-1840, iniciaram a conquista da região dando origem à fundação de inúmeras novas repúblicas,

Naquele ambiente, ele [o pai] bebe avidamente, bebe descontraidamente naquela mistura de inglês e africâner que é a língua comum deles quando se encontram. Ele gosta dessa lingua dançante, com trechos que escorregam aqui e ali na sentença. É mais leve e arejado do que o africâner que se estuda na escola, - mais pesado, com expressões que devem vir do volksmond, da boca das pessoas comuns -mas que parece mesmo vir da Great Trek, indolentes, expressões sem sentido, a respeito de carroças, gado, e arreios (COETZEE, 1998, p. 81).

Ainda que, em ocasiões como a focalizada, o garoto de Boyhood se sinta confortável em falar e entender as duas línguas, usando-as numa espécie de code-switching, Coetzee, ele mesmo, em Doubling the point, escolhe falar sobre si mesmo, recorrentemente, em terceira pessoa. Parte da descrição de sua infância, na cidade rural de Worcester, pode ser resumida a seguir. Ao relembrar a infância, aponta algumas de suas aflições sobre a incerteza na escolha da língua em situações específicas; o escritor tenta explicar o sentimento de estranhamento que o persegue desde a meninice, em forma de pesadelos,

[...] uma criança de origem africâner que assistia aulas em inglês, numa época de ferrenho nacionalismo africâner em que as leis eram criadas para evitar que pessoas de descendência africâner ensinassem inglês a seus filhos, ele tinha pesadelos em que era caçado e acusado; quando tinha 12 anos havia desenvolvido um senso de marginalidade social (COETZEE, 1992, p. 393).

A família do protagonista, em Boyhood, poderia ser avaliada como de africâners, moradores de uma região de africâners, contudo, ele estudava em escola inglesa, falavam inglês em casa, os pais davam nomes ingleses aos filhos, em uma clara deferência aos ingleses. Sentimentos de não pertencimento afligem o garoto, que se considera, ao mesmo tempo, diferente dos ingleses, já que de origem africâner e, ao mesmo tempo, diferente dos africâners, pelo ambiente em que foi criado. Deixa transparecer certo constrangimento, não exatamente ver- 
gonha, na preferência da língua; embora tenha desejo de ser inglês, ele contradiz seu sentimento de pertencimento em relação à família. O capítulo 15 demonstra confortos e desconfortos de uma criança em relação às duas línguas,

Porque eles [seus pais] falam inglês em casa, porque ele sempre fala primeiro em inglês na escola, ele pensa em si mesmo como um inglês, embora seu sobrenome seja africâner, embora seu pai seja mais africâner do que inglês, embora ele mesmo fale africâner sem nenhum sotaque inglês, ele não poderia, jamais, passar por africâner (COETZEE, 1998, p. 124).

O narrador, sempre em terceira pessoa, conta lembranças sobre a pouca fluência do garoto quando se expressava em africâner - a falta de habilidade em usar gírias e "obscenidades", próprias do que ele chama de "verdadeiros garotos africâners" (COETZEE, 1998, p. 124). Comenta, ainda, sobre a maneira de se comportar que os outros garotos tinham em comum - eram intransigentes, fortes, truculentos - comportamento que ele não lograva compartilhar, evitava encontros, verdadeiramente os temia. Apesar disso, ansiava expressar-se na língua africâner; quando finalmente utrapassou essa barreira, considerou um dia de celebração,

Então, um dia, repentinamente, ele abriu a boca e descobriu que podia falar, falar fácil e fluentemente, sem se interromper para pensar. Ele, ainda se lembra como correu para sua mãe gritando, - Ouça! Eu consigo falar em africâner!

Quando ele fala africâner, todas as complicações da vida parecem de repente desaparecer. O africâner é como um envelope fantasmagórico que o acompanha a todos os lugares, e que ele se sente livre para se enfiar, tornando-se imediatamente uma pessoa mais simples, mais feliz, mais leve em sua caminhada (COETZEE, 1998, p. 125).

A insegurança que a escolha da lingua lhe impinge é igualmente sentida no comportamento percebido tanto em africâners como em ingleses; nos últimos, o que mais o desaponta e que, assinala o narrador, jamais os imitará, é o desprezo que demonstram em relação aos africâners ao levantarem as sobrancelhas e pronunciarem mal as palavras naquele idioma, de modo propositado, para que fossem notados como cavalheiros ingleses, "eles estão errrados, piores do que errados, são cômicos" (COETZEE, 1998, p. 125). Ao se expressar naquela língua, ele revela que "não faz nenhum tipo de concessão", ainda que estivesse entre ingleses, ele pronunciaria as palavras em africâner como deveriam ser pronunciadas, "com todas as consoantes duras e as vogais dificeis" (COETZEE, 1998, p. 125).

Por outro lado, o personagem principal também não entendia por que tantas pessoas ao seu redor odiavam a Inglaterra, afinal, "a Inglaterra estava fazendo sua obrigação", elucubrava ele, a Inglaterra representava a cultura, era Sir Lancelot, Robin Hood, tinha histórias medievais, para então questionar, "O que os africâners têm para comparar?” - batalhas, vinganças, ostentação de vitórias sobre africanos nativos desarmados, respondia (COETZEE, 1998, p. 128).

A ambivalência e o contraditório sentimento em relação à língua e aos seus falantes se reproduzem em relação aos africâners, e se evidenciam, da mesma forma, quando o narrador avalia a Inglaterra e os ingleses, e, de modo igual, a aparência das pessoas, 
Existe a lingua inglesa que ele domina com facilidade. Existe a Inglaterra e tudo o que ela representa e que acredita ser leal. Mas mais do que é exigido e, claramente, antes de qualquer um ser aceito como verdadeiramente inglês, há o teste das feições, algo que ele sabe, jamais passará (COETZEE, 1998, p. 129).

A ambivalência da identidade - destino de individuos diaspóricos, consumidos em identidades hifenizadas, paradoxais, parece não ter solução em Boyhood, parece não ter tido solução para J. M. Coetzee, hoje um cidadão nem inglês, nem sul-africano, mas australiano. Lê, escreve, fala perfeitamente o inglês, o africâner, traduz e faz versão, igualmente para ambas, no entanto, ele presume, nos dizeres de Attwell (2015, p. 35-41), não ter afinal o que se pode dizer, uma lingua materna - embora ele tenha nascido no inglês, a naturalidade, as marcas de inglesidade foram gradualmente perdidas; quanto ao africâner, embora nunca tenha sido hostil à língua, ele jamais poderia se considerar culturalmente um africâner, pois isso indicaria a aceitação dos termos do nacionalismo pós-1948, restrita lealdade à identidade linguística, religiosa e política. "Mais e mais", expõe o pesquisador, sobre os rascunhos do livro Summertime (2009), "a língua se torna um corpo estranho que ele tem de entrar. Ele se torna, em seu pensamento, uma pessoa sem lingua, um espirito sem corpo" (ATTWELL, 2015, p. 41). Cabe-nos aqui evocar Stuart Hall (2003, p. 416) acerca da contemporaneidade ser marcada pelo desarraigamento irregular das relações sociais, pela alienação e por processos de destradicionalização, questões colocadas como uma articulação do pós-moderno com o pós-colonial - o último, garante ele, "prepara o individuo para viver uma relação 'pós-moderna' ou diaspórica com a identidade", algo que chama da experiência de estar dentro e estar fora, como condição arquétipica da modernidade tardia; em condições diaspóricas, os indivíduos são como que obrigados a adotar posições de identificação deslocadas, múltiplas (HALL, 2003, p. 76). Retornando aos apontamentos de Attwell (2015, p. 41), vale citar as palavras de Coetzee ao responder à imprensa, logo após ser indicado ao prêmio Nobel, sobre categorizá-lo como "africâner" - ele é suficientemente direto ao interpretar o termo como "grupo identitário": "você não pode simplesmente escolher [o grupo identitário], você terá, também, de ser escolhido"; mais tarde, ao falar sobre a ambivalência e a dubiedade da identidade, ele afirmaria que talvez até pudesse ser um africâner, mas em sentido histórico.

Lugar, língua, identidade são os elementos que nos guiaram na trajetória triangular para tentarmos, parcialmente, entender a relação do texto de Coetzee com os paradoxos da representação binária de ficção/história, do particular/ geral, do presente/passado. Stuart Hall (apud HANNA; BRITO, 2014, p. 107108) reflete sobre os aspectos identitários que surgem a partir do senso de pertencimento a distintos grupos étnicos, raciais, linguísticos, religiosos e, sobretudo, às culturas nacionais, e que servem, no presente estudo, como referência ao questionamento sobre o compartilhamento da cultura, como veremos a seguir. Segundo o teórico, a identidade cultural trata de algo que indivíduos partilham, alusivo às suas origens, experiências históricas, códigos culturais, referências e significados estáveis, atinente à ideia de "vir a ser" tanto quanto à de "ser", conceito que se sobrepõe à noção de tempo tríbio, que comporia o tempo social, o tempo geral, o passado, o presente e o futuro, e que viria a ser permanentemente plural, composto e complexo, sempre sintese de vidas coletivas, "Nunca singular nem simples" (FREYRE, 2001, p. 24). A compreensão de Hall (1990, p. 222-237) 
sobre as identidades culturais, "não é algo que já existe, transcende lugar, tempo, história e cultura. As identidades culturais procedem de algum lugar, elas têm histórias" e, por se tratar de algo histórico, sofre constantes transformações. Algo parecido acontece, como podemos constatar na obra de Coetzee ao observarmos as publicações cronologicamente, desde a primeira ficção, Dusklan$d s$ (1974), que fazia sentido política e filosoficamente na década de 1970, em que estabelece uma narrativa histórica de agressiva violência imperialista em um contexto de colonialismo e descolonização (ATTWELL, 1993, p. 14). Retornando Hall (1990, p. 225), a historicidade diz respeito a elementos universais que condicionam o comportamento de determinada população em uma dada situação, a identidade cultural, portanto, ao praticar contínuas transformações, expõe ele,

Longe de permanecerem eternamente imutáveis em algum passado, são submetidas ao contínuo "jogo" da história, cultura e poder. Longe de estarem fundamentadas numa mera "recuperação" do passado, que está esperando para ser encontrado e, quando encontrado, garantirá o senso de nós mesmos até a eternidade; identidades são os nomes que criamos às diferentes maneiras que nos posicionamos e somos posicionados nas narrativas do passado.

Entendemos que a relação entre o narrador e o tempo histórico acontece no modo como o presente reinterpreta o passado para se representar, criando uma forma pessoal de articular as dimensões temporais, unindo passado e presente de maneira original. No contexto da África do Sul e, particularmente, ao examinar a fundo a obra de Coetzee, Attwell (2015, p. 43) conclui que hoje a carga de culpa histórica carregada pelos falantes de africâner permanece, mas que está se dissipando e é possivel falarmos em "pluralidade de identidades que, de fato, sempre foi intrínseca à história do africâner e de seus falantes, particularmente a diversidade racial de línguas, o aspecto que o nacionalismo branco procurava repudiar". Para concluirmos as considerações acerca da relação identidade-passado, lembremos que cada pessoa deve ser vista como uma sintese do passado, "A construção de nossas identidades só poderá ser compreendida dentro do contexto de sua articulação, na intersecção de nosso cotidiano com as relações políticas e econômicas de subordinação e dominação" (RUTHERFORD, 1990, p. 19-20). Desse modo, não existe raciocínio decisivo que possa nortear e precisar a estrutura da identidade.

\section{CONSIDERAÇÕES FINAIS}

Narratividade, verdade, tempo e lugar em que o escritor vive têm sido objetos de discussão de estudiosos, de críticos, inúmeras vezes acompanhados de debates sobre se o ficcionista foge da realidade histórica ou se verdadeiramente registra em seus escritos, de fato, o tempo e os eventos ocorridos. Como a verdade é representada?

Em Doubling the point, no capitulo intitulado "South African Writers" (p. 341342), Coetzee (1992) responde a perguntas sobre a tendência de a ficção na África do Sul ser absorvida pelo discurso histórico e acabar se tornando, de acordo com as palavras do entrevistador, David Attwell, um mero suplemento de algo documental histórico - Coetzee parece se empenhar em desmistificar a his- 
tória e fazer com que a literatura respeite "uma separação entre a natureza e os propósitos da história e aqueles da ficção, ou pelo menos, alguns tipos de ficção" (ATTWELL, 2015, p. 335). Apesar de manter esse ponto de vista, é reconhecida uma posição historicamentre cúmplice em seus livros; uma orientação discursiva caracteriza sua ficção e estabelece, ao mesmo tempo, uma narrativa histórica que se integra ao contexto do colonialismo e da descolonização da África do Sul, como ele mesmo professa,

Observar a situação da África do Sul [hoje] como somente uma manifestação de uma situação histórica mais ampla para entender o colonialismo, o colonialismo tardio, neo-colonialismo. Desconfio das linhas de divisão entre o contexto europeu e o contexto da África do Sul, porque eu penso que nossa experiência permanece largamente colonial (WATSON, 1978 apud ATTWELL, 1993, p. 14).

Isto apresentado, é importante que mencionemos algumas questões relevantes da teoria pós-colonialista discutidas por Ashcroft e Ahluwalia (2001), no que se refere às repercussões socioculturais sobre as coletividades dominadas, as consequências da educação colonial, os impactos linguísticos, os efeitos de discursos dominadores da história e da filosofia, as ligações entre o conhecimento ocidental e o poder colonial e o modo como dominados responderam a elas. Embora a obra de Coetzee não se apresente abertamente engajada histórica e politicamente no pós-apartheid, e por esse motivo ser alvo de criticas, muitas vezes injustificadas, dado que gestos de resistência são identificados, assim como constatado um comprometimento obliquo em seu posicionamento dentro e fora dos romances, sem transparecer obrigação, no entanto, confessada, de que a literatura devesse ser submissa à história. Head (2009, p. X) assim apresenta os textos do escritor que parecem se fundamentar na ideia de que a literatura não deveria pretender suplementar a história, "a ênfase em questões de textualidade são uma evolução de quesitos pós-modernistas (modernismo tardio) e pós-estruturalismo encontrado em seu contexto" - mas estabelecer uma posição de rivalidade com ela.

Obras literárias, conforme informam Hanna e Bastos (2012, p. 108), devem ter proeminência na relação história-passado, porquanto, mais do que os registros dos historiadores, moldam as representações coletivas, apresentando incertezas e contradições - tanto quanto o discurso histórico o faz. As pesquisadoras apoiam-se em A história ou a leitura do tempo, de Roger Chartier (2009), em que fala a respeito da perturbação que causa a diferenciação entre história e ficção, já que a literatura, além de usurpar o passado, serve-se de seus documentos e de suas técnicas. Além disso, cabe mencionar as palavras do historiador no que concerne à aproximação, à completude e, ao mesmo tempo, à diferenciação entre ficção e história em relação ao passado:

Entre história e ficção, a distinção parece clara e resolvida se se aceitar que, em todas as suas formas (míticas, literárias, filosóficas) a ficção é um "discurso que 'informa' do real, mas não pretende representá-lo nem abonar-se nele”, enquanto a história pretende dar uma representação adequada da realidade que foi $e$ já não é (CHARTIER, 2009, p. 24).

Lembramos, ainda, que história e literatura são discursos, ambas constituem um sistema de significação que dá sentido ao passado; assim, a literatura ficcional é tão somente uma das verdades em sua referencialidade histórica, e não deveria ser adequado avaliá-la como verdadeira ou falsa, ou inconciliável 
com a história; a ficção é apenas uma representação de várias verdades - uma combinação do histórico com o fictício poderia levar a alguma verdade - mas, ainda, seria uma obra de ficção.

Justapondo-se às ideias listadas, cumpre-nos assinalar as ambivalências profundas que constroem ambos os discursos de colonizadores e colonizados, ressaltando, no entanto, a reação dos últimos no sentido da luta pelo controle da autorrepresentação através da apropriação das linguas dominantes, discursos e formas de narrativa. Embora assuntos como "a luta a respeito das representações de lugar, história, raça e etnicidade, e a luta para apresentar a realidade local para uma audiência global" (ASHCROFT; AHLUWALIA, 2001, p. 15) sejam orientados pela teoria literária representada pela literatura escrita por (ex) colonizados, na lingua do colonizador (particularmente em inglês), acabam por ser aproveitados em análises históricas, politicas, sociológicas, e linguísticas.

Prosseguimos com Attwell (1993, p. 14), em J. M. Coetzee: South Africa and the Politics of Writing, para compartilhar sua avaliação, em que atesta que a narrativa da obra de Coetzee é do colonialismo e da descolonização e que tem início com o livro Dusklands (1974, violência imperialista), seguido por In the Heart of the Country (1977, uma fábula sobre a opressão); Waiting for the Barbarians (1980, revolução quase antecipada), e Life and Times of Michael K (1983, guerra civil aberta), ideia que completa análise anterior em que avaliza que a luta que o escritor trava com a História está codificada em prosa narrativa, presente em todo o seu trabalho. Resta-nos destacar que Coetzee resgata com frequência o tema e, em Doubling the point, ele tenta eximir-se do dever de narrar a verdade, quando declara, "nós temos arte, portanto não podemos morrer com a verdade" o que responde, em parte, àqueles que estão à procura de respostas categóricas, "na África do Sul, há, atualmente, verdade demais para que a arte consiga abrigá-la, verdade aos montes, verdade que oprime e inunda todo ato de imaginação" (COETZEE, 1992, p. 99). A pergunta recorrente se apresenta implícita no questionamento do escritor: afinal, como a verdade deve ser narrada?

Questões como estas nos remetem ao tratamento que Attwell (1993) dá à metaficção pós-moderna na obra de Coetzee, quando discorre a respeito da relação textual na cultura literária pós-moderna referindo-se à história e aos discursos históricos e políticos. O estudioso destaca que a língua, como elemento de consciência e de cultura, revela, no trabalho de Coetzee, em sua narrativa histórica, o seu lugar histórico no momento do colonialismo e do apartheid, assim como os conflitos sociais, as questões étnicas e politicas, e, em seguida, as da descolonização, conforme se deduz no seguinte excerto:

Em seu ponto de vista, o discurso narrativo é, sem dúvida, historicamente enraizado - sem dúvida, a História exerce uma presença tirânica - mas de modo mais significativo, Coetzee está interessado nas consequências desse enraizamento. Se a História é uma força determinante e circunscrita, a questão permanece - que forma de vida está disponivel para a prosa narrativa se ela tenta negociar aquela determinação e circunscrição? (ATTWELL, 1993, p. 10).

O discurso narrativo reside no escritor e é, também, o meio de ligação com o ambiente social, perceptível em quase todos os seus livros; Attwell (1993) destaca a posição do escritor, e de sua relação com a sociedade, que, advinda da maneira como transmite o discurso de ficção, é assim interpretada. A ideia se completa em, 
A posição de Coetzee implica que a narrativa é, ela mesma, um produto histórico, existindo em tensão com outros discursos do momento que são, além disso, produtos da história e portadores da cultura. Em termos de tal posicionamento, poderia se perguntar, portanto, qual seria uma autodefinição apropriada de escritor, mas em vez disso, quais formas de autodefinição estão disponíveis dentro da cultura - disponíveis, isto é, para o escritor, cuja relação com a sociedade repousa na maneira pela qual ele transmite os discursos de ficção (ATTWELL, 1993, p. 13).

Para concluirmos as considerações acerca da relação identidade-passado, lembremos que cada pessoa deve ser vista como uma síntese do passado, "a construção de nossas identidades só poderá ser compreendida dentro do contexto de sua articulação, na intersecção de nosso cotidiano com as relações políticas e econômicas de subordinação e dominação" (RUTHERFORD, 1990, p. 19-20). Desse modo, não existe raciocínio decisivo que possa nortear e precisar a estrutura da identidade. Vale transcrevermos a percepção de Hall (2005, p. 502), "a identidade cultural não é fixa, mas constantemente híbrida, pois é proveniente de formações históricas específicas, de histórias igualmente específicas e de repertórios culturais de enunciação", e, por esse motivo, "pode constituir um 'posicionamento' que podemos chamar provisoriamente de identidade" e, assim, a consideramos na análise que por ora concluímos. Pela razão de que cada história identitária está inscrita nas posições que assumimos e com as quais nos identificamos, devemos viver cada conjunto de posições identitárias em todas as suas especificidades. Completamos, dessa forma, o entendimento de Highmore (2002a, p. 3), de bizarrice e mistério que envolve o cotidiano, "os lugares comuns da existência são repletos de ocorrências estranhas" ao que acrescenta que "o não-cotidiano (o excepcional) deve ser procurado no âmago do cotidiano", o terreno ambivalente da modernidade deve, forçosamente, ser investigado.

\title{
The PRACTICe of EVeryday LIFe in J. M. Coetzee: language and IDENTITY IN BOYHOOD, SCENES OF PROVINCIAL LIFE, A MEMOIR (1998)
}

\begin{abstract}
The aim of this study is to exam J. M Coetzee's intricate attitudes towards the English and the Afrikaans languages in his writings, and by extension his own ideas on the sense of both languages in Boyhood, scenes of provincial life, a memoir (1998). We will consider passages of the (autre)biography (fictionalized autobiography) exploring the issue of identity and choice-use of language in South Africa. Furthermore, the essay looks for understanding the reletionship of his text with the paradox of binary representation fiction/history, private/general, present/past.
\end{abstract}

Keywords: Language. Identity. J. M. Coetzee. 


\section{REFERÊNCIAS}

ASHCROFT, B.; AHLUWALIA, P. Routledge Critical thinkers essential guides for literary studies. Edward Said. New York: Routledge, 2001.

ATTWELL, D. J. South Africa and the Politics of Writing. Berkeley; Los Angeles; Oxford: University of California Press, 1993. Disponivel em: <http:/ / publishing. cdlib.org/ucpressebooks/view?docId=ft5k4006q3; brand=eschol>. Acesso em: 23 maio 2016.

ATTWELL, D. J. M. Coetzee and the life of writing; face to face with time. Oxford: Oxford University Press, 2015.

BHABHA, H. K. O local da cultura. Tradução Myriam Ávila et al. 3. ed. reimp. Belo Horizonte: Editora UFMG, 2005.

BURKE, P. A escrita da história: novas perspectivas. Tradução Magda Lopes. São Paulo: Editora Unesp, 1992.

CHARTIER, R. A história ou a leitura do tempo. Tradução Cristina Antunes. Belo Horizonte: Autêntica Editora, 2009.

COETZEE, J. M. Dusklands. Johannesburg: Ravan Press, 1974.

COETZEE, J. M. In the heart of the country. Johannesburg: Ravan Press, 1977.

COETZEE, J. M. Waiting for the barbarians. Harmondsworth: Penguin, 1980.

COETZEE, J. M. Life and times of Michael K. Harmondsworth: Penguin, 1983.

COETZEE, J. M. Doubling the point: essays and interviews. Editado por David Atwell. Cambridge: Harvard University Press, 1992.

COETZEE, J. M. Boyhood, scenes of provincial life, a memoir. New York: Penguin Books, 1998.

COETZEE, J. M. Summertime. London: Harvill Secker, 2009.

DE CERTEAU, M. General Introduction to the Practice of Everyday Life [1980]. In: HIGHMORE, B. (Ed.). The Everyday Life Reader. New York: Routledge. 2002. p. 63-75.

FREYRE, G. Além do apenas moderno. 2. ed. Rio de Janeiro: Topbboks, 2001.

HALL, S. Cultural identity and diáspora. In: RUTHERFORD, J. (Ed.). Identity: community, culture, difference. London: Lawrence Wishart, 1990. p. 222-237.

HALL, S. Da diáspora, identidades e mediações culturais. Tradução Adelaine La Guardia Resende et al. Belo Horizonte: Editora UFMG, 2003.

HALL, S. Critical dialogues in cultural studies. Edited by David Morley and Kuan-Hsing Chen. New York: Routledge, 2005.

HANNA, V. L. H.; BASTOS, N. M História do presente e historiografia linguística: implicações. In: BASTOS, N. B.; PALMA, D. V. História entrelaçada 5: estudos sobre a linguagem em materiais didáticos - década de 1950. São Paulo: Educ, 2012. p. 17-34.

HANNA, V. L. H.; BRITO, R. P. Busca identitária em espaço lusófono: Timor-Leste. In: BASTOS, N. B. Lingua Portuguesa e lusofonia. São Paulo: Educ, 2014. p. 105-118.

HEAD, D. The Cambridge introduction to J. M. Coetzee. New York: Cambridge University Press, 2009. 
HIGHMORE, B. Everyday life and cultural theory: an introduction. New York: Routledge, 2002a.

HIGHMORE, B. (Ed.). The everyday life reader. New York: Routledge, 2002b.

KEATING, A. L. (Ed.). The Gloria Anzaldua reader. Durham: Duke University Press, 2009.

PAMUK. O. Other countries, other shores. New York Times. Dec. 19, 2013. Disponivel em: <http://www.nytimes.com/2013/12/22/books/review/other-countries-other-shores.html?_r=1>. Acesso em: 10 jun. 2016.

RUTHERFORD, J. A place called home: identity and the cultural politics of difference. In: RUTHERFORD, J. (Ed.). Identity: community, culture, difference. London: Lawrence Wishart, 1990. p. 9-27.

Recebido em agosto de 2016. Aprovado em novembro de 2016. 